\title{
Radical-enhanced Acidity: Why Bicarbonate, Carboxyl, Hydroperoxyl and Related Radicals Are So Acidic
}

\author{
John C. Walton.* \\ EaStCHEM School of Chemistry, University of St. Andrews, St. Andrews, Fife, KY16 9ST, United Kingdom.
}

Supporting Information

\begin{abstract}
Comparison of accepted $p K_{a}$ values of bicarbonate, carboxyl and hydroperoxyl radicals, with those of models having the unpaired electron replaced by $\mathrm{H}$-atoms, implied the acidity of the radicals was greatly increased. A DFT computational method of estimating $p K_{a} \mathrm{~s}$ was developed and applied to a set of radicals designed to probe the phenomenon of Radical-Enhanced Deprotonation (RED-shift) and its underlying causes. Comparison of the computed $p K_{a}$ values of twelve acid radicals to those of the corresponding model acids confirmed the intensified acidity of the title radicals and also pin-pointed the carboxy-ethynyl $\left(\mathrm{HO}_{2} \mathrm{CC} \equiv \mathrm{C}^{\circ}\right)$ and the carboxy-aminyl $\left(\mathrm{HO}_{2} \mathrm{CNH}^{*}\right)$ radicals as having enhanced acidity. The underlying cause was found to be extensive charge distribution away from the anionic O-atoms of the conjugate radical anions, coupled with spin density displaced towards these Oatoms. Ethyne spacers, between the radical and carboxylate centers, transmitted the effect extremely efficiently such that measurable enhancement was detectable up to at least six alkyne units. The bicyclo[1.1.1]pent-1-yl-3-carboxylic acid radical also displayed enhanced acidity but additional cage units drastically attenuated the effect. Nitroxide radicals with suitably situated carboxylic acid substituents also exhibited enhanced acidity. Several families of potentially persistent radicals with enhanced acidity were identified.
\end{abstract}

\section{INTRODUCTION}

Several notable free radicals are strong Brønsted-Lowry acids and exist as acid/conjugate base pairs in aqueous solutions. These include the neutral bicarbonate radical/bicarbonate radical-anion pair $\left[\mathrm{HOC}(\mathrm{O}) \mathrm{O}^{\circ} \% \mathrm{OC}(\mathrm{O}) \mathrm{O}^{\bullet}\right],{ }^{1,2, \square}$, the carboxyl radical/carboxylate radical anion pair $\left[{ }^{\bullet} \mathrm{C}(\mathrm{O}) \mathrm{OH} /{ }^{\bullet} \mathrm{C}(\mathrm{O}) \mathrm{O}^{-}\right]^{\square, \square}$ and the hydroperoxyl/superoxide pair $\left[\mathrm{HOO}^{\circ} / \mathrm{OO}^{\bullet}\right] . \square, \square$ All six species are short-lived and play crucial roles in the environment and in the biological fluids of living organisms. In each instance one partner is neutral and the other is anionic so the preferred reaction modes and the reactivities of the partner species differ markedly. To understand their environmental and biological impact it is essential, therefore, to ascertain the characteristics of each partner and the proportions present. Accordingly, the factors that control their dissociation, together with their $p K_{a} \mathrm{~s}$, constitute essential information.

Determinations of the acid dissociation constants of such short lifetime species by experiment were problematic. Experimental and computational evidence suggested the bicarbonate radical was strongly acidic with a $p K_{a}<0 ; ;^{1 \square, 11,12,1}$ recent research into its microsolvation pointed to a $p K_{a}$ of $\sim$ -2.4 units. ${ }^{1 \square}$ The most reliable value of the $p K_{a}$ of the carboxyl radical (-0.2) was obtained from a ground-breaking EPR spectroscopic study by Fessenden and co-workers. ${ }^{1 \square}$ The $p K_{a}$ of the hydroperoxyl (perhydroxyl) radical (4.88) was determined more conventionally from several studies of the interaction of superoxide with weak acids. ${ }^{1 \square, 1 \square, 1 \square}$

A comparison of these radical $p K_{a}$ s with those of model acids having the unpaired electrons (upe) replaced by $\mathrm{H}$-atoms was very intriguing. In the case of the bicarbonate radical the model, carbonic acid $(\mathrm{HOC}(\mathrm{O}) \mathrm{OH})$, has $p K_{a}=3.6$; about 6 $\log$ units less acidic! Model acids formic $(\mathrm{HC}(\mathrm{O}) \mathrm{OH})$ and hydrogen peroxide $(\mathrm{HOOH})$ have $p K_{a} \mathrm{~s}$ of 3.76 and $11.75,{ }^{19,2 \square, 21}$ differing by nearly 4 and $7 \log$ units from the corresponding carboxyl and hydroperoxyl radicals respectively. Clearly, replacement of an $\mathrm{H}$-atom by an upe, in these structures, strongly enhanced deprotonation and large increases in acidity resulted. Hayon and Simic previously reviewed the acid/base properties of radicals and noted that their ionization constants can be much lower than those of parent compounds. ${ }^{22}$ Radom and co-workers also concluded that "In general, the $\mathrm{CH}_{3} \mathrm{WOH}$ alcohols were found to be less acidic than the related ${ }^{\circ} \mathrm{CH}_{2} \mathrm{WOH}$ radicals" (W represents connector groups) from their computational studies on the gas phase BDEs and acidities of alcohols. ${ }^{2 \square, 2 \square, 2 \square}$ The present investigation was undertaken to explore the extent and magnitude of this phenomenon of Radical-Enhanced Deprotonation; hereafter dubbed a molecular 'RED-shift'. Do other radicals display enhanced acidity? What structural features are needed for the phenomenon to occur? Can underlying stereoelectronic factors be identified? 


\section{COMPUTATIONAL DETAILS}

DFT calculations were carried out using the Gaussian 09 suite of programs. ${ }^{2}$ The CAM-B3LYP functional with the 6-311+G(2d,p) basis set was employed for most species with the $\mathrm{CPCM}$ continuum model ${ }^{41}$ with water as solvent. Vibrational frequency calculations were implemented so that GS (no imaginary frequencies) and TS status could be checked (one imaginary frequency) and enthalpies and free energies were adjusted for zero point and thermal corrections to $1 \mathrm{~atm}$ and $298 \mathrm{~K}$.

\section{RESULTS AND DISCUSSION}

\section{Method for $p K_{a}$ Computation}

As mentioned above, the experimental $p K_{a}$ s of short-lived radicals may be unreliable. An easily applicable computational method of assessing radical $p K_{a}$ s that would give dependable data was therefore sought. There is an extensive literature on the computation of acid dissociation constants, ${ }^{2 \square, 2 \square}$ including carboxylic acids, $, 29, \square \square, \square 1, \square 2$ and other organic compounds. ${ }^{\circ} \square \square, \square \square$ Pulay and co-workers described an attractively straight-forward and comparatively accurate method (for particular classes of compounds) based on linear correlations of computed deprotonation free energies $\Delta G_{A-H A}$ with experimental $p K_{a} s . \square$ For stable organic acids in water they employed the COSMO solvation model at the OLYP/6-311G**//OLYP/3-21G(d) level. However, a recent validation study specifically for radical species, ${ }^{14}$ compared results obtained with 23 DFT functionals (and the MP2 ab initio method) for a 12 reaction set with results from the high level composite ab initio G4 method. ${ }^{\square}$ The CAMB3LYP functional ${ }^{\square}$ gave the lowest mean absolute deviation and proved to be the best choice.

Deprotonation free energies were therefore computed for model species with the CAM-B3LYP functional, the 6$311+\mathrm{G}(2 \mathrm{~d}, \mathrm{p})$ basis set and using the $\mathrm{CPCM}^{41}$ continuum model with water as solvent. The experimental free energy of solvation for the proton $\left(-264.2 \mathrm{kcal} \mathrm{mol}^{-1}\right)^{\square 2}$ was included. In this way $\Delta G_{A-H A}$ values were computed for 15 organic acids with known $p K_{a}$ s. A satisfactory linear correlation $\left(R^{2}=0.944\right)$ was obtained for this set (see Supporting Information and Figure S1):

$$
p K_{a}=0.287 \Delta G_{A-H A}+0.013
$$

As expected, the data point for $\mathrm{HOOH}$ was somewhat of an outlier to the main line for carboxylic acids. Except for this, equ. (1) returned all $p K_{a} \mathrm{~s}$ within $1 \log$ unit of experiment. In particular, the $p K_{a}$ s for the bicarbonate, carboxyl and hydroperoxyl radicals obtained from equ. (1) [-1.2, -0.1 and 5.1 respectively] were all fairly close to the experimental or estimated values. There was good expectation therefore that realistic estimates for the $p K_{a} \mathrm{~s}$ of other transient acidic radicals could thereby be obtained.

\section{Comparison of Deprotonations of Transient Radicals with Non-radical Models.}

A key factor will undoubtedly be the thermodynamic stabilization of the radical anions formed on deprotonation. The set of acid radicals shown in Scheme 1 was then chosen to test the influence of the upe on the dissociation of nearby carboxylic acid groups. Model radicals in which the upes were replaced by $\mathrm{H}$-atoms are shown to the left.

\section{Scheme 1. Test Set of Transient Acidic Radicals and Model Acids.}

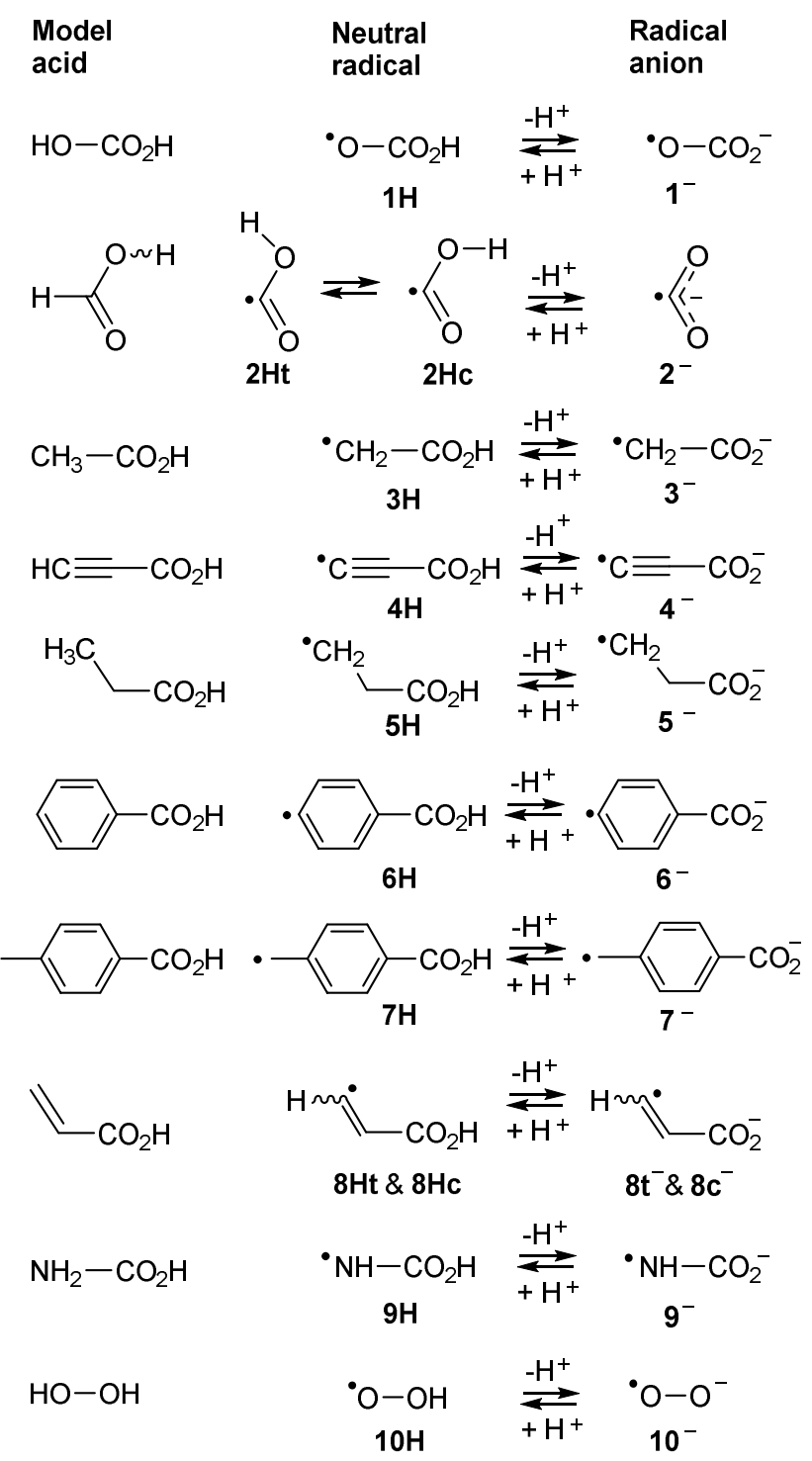

The carbonate radical anion $\mathbf{1}^{-}$may be viewed as a negatively charged carboxylate group formally 'separated' from an upe by an O-atom. In the carboxylate-aminyl radical anion $\mathbf{9}^{-}$the spacer was an $\mathrm{N}$-atom. In carboxyl radical anion $\mathbf{2}^{-}$the upe resided right on the carboxylate carbon. In radical anions $3^{-}$to $\mathbf{8}^{-}$carbon-based spacers of increasing size, some of which were potentially conjugating, formally separated the upe and the negative charge. The superoxide radical anion $\mathbf{1 0}^{-}$added a new dimension in that the negative charge and upe shared adjacent O-atoms. 
The computed deprotonation free energies $\Delta G_{A-H A}$ of these acid radicals are listed in Table 1 ; together with the $p K_{a}$ values derived by use of equ. (1). The electronic charges $(q(\mathrm{O}))$ and spin densities $(\rho(O))$ on the carboxylate $\mathrm{O}$-atoms of the conjugate radical anions were also computed. In the cases where the two carboxylate $\mathrm{O}$-atoms were inequivalent $\left(\mathbf{1}^{-}\right.$, $\left.\mathbf{5}^{-}, \mathbf{8 t}^{-} \& \mathbf{8} \mathbf{c}^{-}\right)$the average was taken. For a meaningful comparison, the same data (excluding $\rho(O)$ of course) was obtained for the conjugate anions of the model acids in which $\mathrm{H}$-atoms replaced the upe.
For the set of acid radicals the computed $\Delta G_{A-H A}$ covered a wide range ( -4 to $18.8 \mathrm{kcal} \mathrm{mol}^{-1}$ ) and the corresponding $p K_{a}$ s ranged from -1.2 to 5.4 units (Table 1). The carboxyl radical $\mathbf{2 H}$ adopts both trans- and cis-conformations having somewhat different deprotonation energies. Data for both is included in Table 1 as well as for the trans- and cis-acrylic acid radical isomers $(\mathbf{8 H t} \& \mathbf{8 H c})$.

Table 1. DFT Computed Properties for Acid Radicals, Conjugate Radical Anions and Model Conjugate Anions.

\begin{tabular}{|c|c|c|c|c|c|c|}
\hline acid dissociation & $\begin{array}{l}\Delta G_{A-H A} \\
\mathrm{kcal} / \mathrm{mol}\end{array}$ & $\begin{array}{c}p K_{a}^{d t} \\
\text { (equ. 1) }\end{array}$ & $\begin{array}{l}p K_{a}^{e x} \\
\text { (expt.) }\end{array}$ & $\Delta p K_{a}^{\dagger}$ & $\begin{array}{c}q(O)^{\S} \\
\mathrm{AU}\end{array}$ & $\rho(O)^{\S}$ \\
\hline $\mathbf{1 H}$ to ${ }^{-} \mathrm{OC}(\mathrm{O}) \mathrm{O}^{-}$ & -3.98 & -1.16 & {$[-2.4]^{\#}$} & 4.76 & -0.577 & 0.370 \\
\hline$-\mathrm{OC}(\mathrm{O}) \mathrm{OH}$ & & 3.04 & 3.6 & & -0.747 & - \\
\hline $2 \mathrm{Hc}$ to ${ }^{-} \mathrm{OC}\left({ }^{\bullet}\right)(\mathrm{O})$ & -0.27 & -0.09 & -0.2 & 3.85 & -0.557 & 0.121 \\
\hline $2 \mathrm{Ht}$ to ${ }^{-} \mathrm{OC}\left({ }^{\circ}\right)(\mathrm{O})$ & 2.11 & 0.59 & -0.2 & 3.17 & -0.557 & 0.121 \\
\hline${ }^{-} \mathrm{OCH}(\mathrm{O})$ & & 3.77 & 3.76 & & -0.700 & - \\
\hline $\mathbf{3} \mathbf{H}$ to $\left(^{\circ}\right) \mathrm{CH}_{2} \mathrm{C}(\mathrm{O}) \mathrm{O}^{-}$ & 18.22 & 5.22 & & -0.46 & -0.763 & 0.074 \\
\hline $\mathrm{CH}_{3} \mathrm{C}(\mathrm{O}) \mathrm{O}^{-}$ & & 4.79 & 4.76 & & -0.753 & - \\
\hline $\mathbf{4 H}$ to $\left(^{\bullet}\right) \mathrm{C} \equiv \mathrm{CCOO}^{-}$ & -2.99 & -0.87 & & 2.71 & -0.593 & 0.133 \\
\hline $\mathrm{HC} \equiv \mathrm{CCOO}^{-}$ & & 2.72 & 1.84 & & -0.693 & - \\
\hline $\mathbf{5} \mathbf{H}$ to $\left(^{\circ}\right) \mathrm{CH}_{2} \mathrm{CH}_{2} \mathrm{COO}^{-}$ & 18.83 & 5.40 & & -0.53 & -0.749 & 0.004 \\
\hline $\mathrm{CH}_{3} \mathrm{CH}_{2} \mathrm{COO}^{-}$ & & 5.03 & 4.87 & & -0.763 & - \\
\hline $6 \mathrm{H}$ to $4-\left(^{\circ}\right) \mathrm{C}_{6} \mathrm{H}_{4} \mathrm{COO}^{-}$ & 15.68 & 4.49 & & -0.303 & -0.764 & -0.002 \\
\hline $\mathrm{PhCOO}^{-}$ & & 4.02 & 4.19 & & -0.766 & - \\
\hline $7 \mathrm{H}$ to $\left(^{\circ}\right) \mathrm{CH}_{2} \mathrm{C}_{6} \mathrm{H}_{4} \mathrm{COO}^{-}$ & 16.51 & 4.73 & & -0.37 & -0.765 & 0.019 \\
\hline $4-\mathrm{CH}_{3} \mathrm{C}_{6} \mathrm{H}_{4} \mathrm{COO}^{-}$ & & 5.00 & 4.36 & & -0.767 & - \\
\hline $\left.8 \mathrm{Ht}^{\text {to }} t-^{(}\right) \mathrm{CH}=\mathrm{CHCOO}^{-}$ & 15.53 & 4.26 & & -0.013 & -0.734 & 0.008 \\
\hline $8 \mathrm{Hc}$ to $\mathrm{c}-\left(^{\bullet}\right) \mathrm{CH}=\mathrm{CHCOO}^{-}$ & 14.88 & 4.45 & & -0.199 & -0.739 & -0.002 \\
\hline $\mathrm{CH}_{2}=\mathrm{CHCOO}^{-}$ & & 4.79 & 4.25 & & -0.755 & - \\
\hline $9 \mathrm{H}$ to $\left(^{\circ}\right) \mathrm{NHCOO}^{-}$ & 7.77 & 2.22 & & $1.7^{\#}$ & -0.703 & 0.083 \\
\hline $\mathrm{NH}_{2} \mathrm{COO}^{-}$ & & 5.82 & {$[3.92]^{\#}$} & & -0.783 & - \\
\hline $10 \mathrm{H}$ to $-\mathrm{OO}\left({ }^{\circ}\right)$ & 17.64 & 5.05 & 4.88 & 6.69 & -0.500 & 0.500 \\
\hline$-\mathrm{OOH}$ & & 10.48 & 11.75 & & -0.861 & - \\
\hline
\end{tabular}

$\S$ The data for $q_{o}$ and $\rho_{o}$ are for the conjugate radical anions. ${ }^{\dagger}$ Difference of experimental $p K_{a}^{e x}-p K_{a}^{d t}$. ${ }^{\#}$ Estimate (see ref. 14); an empirically estimated $p K_{a}^{e x}$ of 3.92 was used for $\mathrm{NH}_{2} \mathrm{COOH}$.

Column 5 displays the difference $\left(\Delta p K_{a}\right)$ between the experimental $p K_{a}^{e x}$ values of the model non-radical acids and the computed $p K_{a}^{d t}$ values of the corresponding acid radicals. $\Delta p K_{a}$ is a quantitative measure of the RED-shift and ranges from $\sim-0.5$ units denoting nil RED-shift up to nearly 7 units for the massive RED-shift of hydroperoxyl $\mathbf{1 0 H}$ (see Figure $1)$.

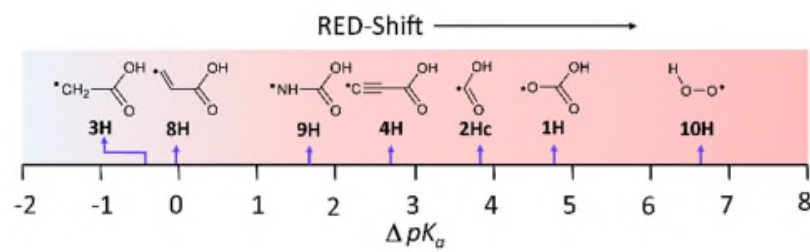

Figure 1. Sequence of $\Delta p K_{a}$ values for selected acid radicals.

Radicals 5H, 6H, 7H and 8Ht\&c had similar acidity to their model acids. In these radicals the upe was well separated 
from the carboxylate group by $\mathrm{CH}_{2} \mathrm{CH}_{2}, \mathrm{C}_{6} \mathrm{H}_{4}, \mathrm{CH}_{2} \mathrm{C}_{6} \mathrm{H}_{4}$ and $\mathrm{CH}=\mathrm{CH}$ groups respectively. In each instance the structure precluded significant influence of the upe on the acid dissociation. For radicals $\mathbf{3 H}, \mathbf{9 H}$ and $\mathbf{1 H}$ the upe resided (formally) on $\mathrm{CH}_{2}, \mathrm{NH}$ and $\mathrm{O}$ centers respectively that were attached to carboxylate carbons. The $\Delta p K_{a}$ values dramatically increased from -0.46 to 1.7 to 4.76 indicating a huge increase in acidity across the set, as the electronegativity of the radical center increased. The $\Delta p K_{a}$ values of the carboxyl radicals (2Hc and $\mathbf{2 H t}$ ) confirmed their large increase in acidity compared to the models. The huge $\Delta p K_{a}$ of the hydroperoxyl radical $(\mathbf{1 0 H})$ also confirmed its exceptional induced acidity. Intriguingly, the carboxy-ethynyl radical $\mathbf{4 H}$, with its upe separated from the carboxylate group by a $\mathrm{C} \equiv \mathrm{C}$ triple bond, had $\Delta p K_{a}=2.71$ and was much more acidic than the H-containing model acid.

The distribution of charge and spin in the conjugate radical anions will influence their ease of solvation and their thermodynamic stabilization. The charges and spin densities associated with the carboxylate $\mathrm{O}$-atoms of the radical and non-radical conjugate anions differ markedly for some species (Table 1). Figure 2(a) shows a plot of the differences between the charges on the carboxylate $\mathrm{O}$-atoms of the model anions from those on the conjugate radical anions $[\Delta q(O)=q(O$-model $)-q(O$-radical anion $)]$ against $\Delta p K_{a}$. It was evident that $\Delta q(O)$ increased smoothly (became more negative) the more the acidity of the radicals increased relative to the non-radical models. The increasingly negative $\Delta q(O)$ signified re-location of charge away from the Oatom(s) of the radical anions. The smoothness of the trend is impressive considering that the data set includes superoxide and carbonate anions as well as carboxylates.

The computed spin densities $\rho(O)$ on the anionic O-atoms of radicals $\mathbf{3 H}, \mathbf{5 H}, 6 \mathbf{H}, \mathbf{7 H}, \mathbf{8 H c}$ and $8 \mathrm{Ht}$ were close to zero (Table 1). The experimental EPR spectra confirmed that spin delocalization was negligible for these radicals. For each of them their isotropic EPR hyperfine splittings were very similar to those of the corresponding radicals lacking the $\mathrm{CO}_{2} \mathrm{H}$ group. $\square \square$ Predictably, therefore, this subset of radicals had nearly the same acidity as their models $\left(\Delta p K_{a}-0.5\right.$ to $\sim$ $0)$.

The spin densities of the radicals $\rho(O)$ were also plotted against $\Delta p K_{a}$ in Figure 2(b). The graph shows some scatter but a trend appeared. As the radicals became relatively more acidic, that is as $\Delta p K_{a}$ increased, so $\rho(O)$ also increased. The overall pattern was that enhanced acidity in the radicals correlated with charge delocalized away from the anionic $O$ atoms, coupled with spin density relocated towards these $O$ atoms. Effectively this was a site exchange of spin with charge. The carboxyl (2Ht\&c) radicals achieved this because charge and spin were on adjacent atoms in their conjugate anions. Hydroperoxyl (10H) was distinctive because both charge and spin were equally shared between the two equivalent and adjacent $\mathrm{O}$-atoms of the superoxide radical anion $\mathbf{1 0}^{-}$. The carbonate radical anion $\mathbf{1}^{-}$from $\mathbf{1 H}$ was also unique in having charge and spin symmetrically distributed to three $\mathrm{O}$-atoms.

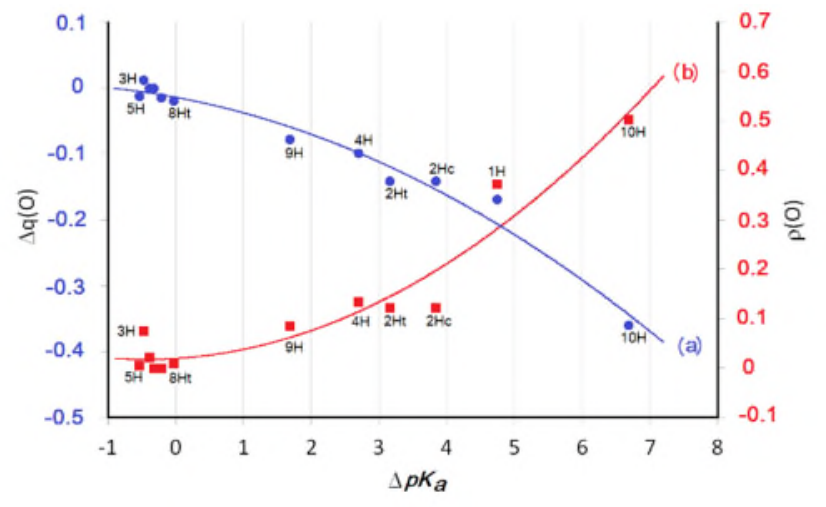

Figure 2. Plots of: (a) relative charge (blue) on the anionic O-atoms $[q(O)]$ and (b) of spin density (red) on the carboxylic O-atoms $[\rho(O)]$ against relative $p K_{a}$. of acid radicals.

The carboxylate-ethynyl radical anion $\mathbf{4}^{-}$was a particularly interesting case. Although the upe appeared to be well separated from the carboxylate on conventional structure representations, the carboxy-ethynyl radical $\mathbf{4 H}$ was nonetheless a much stronger acid $\left(\Delta p K_{a}=2.71\right)$ than its model. The computed distribution of charge and spin in $\mathbf{4}^{-}$is presented in Figure 3 and compared with that of the carboxylate-methyl radical anion $3^{-}$. The data demonstrated that the charge on $3^{-}$remained essentially associated with the $\mathrm{O}$-atoms of the carboxylate group while the spin remained localized on the $\mathrm{CH}_{2}$ group. Hence there was no enhanced acidity. For $\mathbf{4}^{-}$on the other hand, much of the negative charge was delocalized from the carboxylate to the terminal ethynyl $\mathrm{C}$-atom $(-0.935)$ and spin density was distributed away from the terminal ethynyl $\mathrm{C}$-atom such that significant spin density even reached the carboxylate $\mathrm{O}$-atoms (0.132). This is an apt demonstration of the exchange pattern mentioned above.
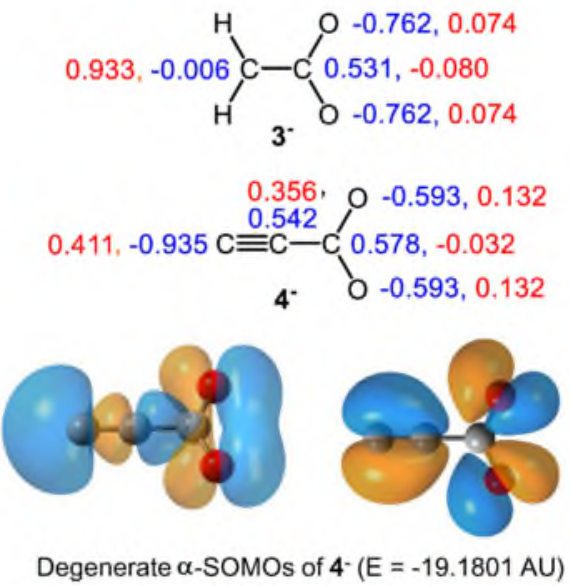

Figure 3. Above: Mulliken charges $[q(O)$, blue $]$ and spin densities $[\rho(O)$, red] with $\mathrm{H}$-atoms summed into heavy atoms. Below: HOMO orbital amplitude surfaces for $4^{-}$. Data at the CAM-B3LYP/6-311+G(2d,p) level. 
Conventionally, the ability of acetylenic C-atoms to accommodate negative charge has been attributed to the comparatively large $s$-character of the orbitals. For radical anion $4^{-}$ the DFT computations yielded the two degenerate HOMOs displayed in Figure 3. These orbitals distribute amplitude throughout the whole structure. Furthermore the significant $s$-character at the terminal ethynyl C-atom of the $\sigma$-orbital on the left rationalizes the ability of $\mathbf{4}^{-}$to support negative charge at this site.

\section{Scope and Range of the RED-Shift}

The structures of radicals exhibiting a RED-shift permitted exchange of charge and spin in their conjugate radical anions. The small radical anions $\mathbf{1}^{-}, \mathbf{2}^{-}$and $\mathbf{1 0}^{-}$achieved this because of their structural symmetry and the close proximity of the (formal) spin to the charge. When charge and spin were separated by saturated chains, even as short as $\mathrm{CH}_{2}$ (see 3H, Table 1), no enhancement resulted. Separation of charge and spin by aromatic rings or by $\mathrm{C}=\mathrm{C}$ double bonds also led to virtually no RED-shift (see Table 1). The charge/spin separation in the carboxy-ethynyl radical $\mathbf{4 H}$ was comparatively large. A $\sigma$-type orbital was associated with the ethyne linker unit (see Figure 3) and this facilitated the charge/spin exchange. Chart 1 presents a series of radicals $11 \mathrm{H}$ to $15 \mathrm{H}$ in which the number of ethyne units was increased from 1 to 6 . This series was examined to further explore the range of the RED-shift.

The deprotonation free energies $\left(\Delta G_{A-H A}\right)$ for dissociation of each radical were computed by the method described above. Similarly, the $\Delta G_{A-H A}$ values for model acids corresponding to each of $11 \mathrm{H}$ to $15 \mathrm{H}$, but with their upes replaced by $\mathrm{H}-$ atoms, were also computed. The corresponding $p K_{a}$ and $\Delta p K_{a}$ were then obtained by use of equ. (1). This data, together with charge and spin values, is in Table 2.

The upes of cage bridgehead radicals are contained in $\sigma$-orbitals. Furthermore, the smaller cages are known to transmit spin density across their centers. $\square$, As judged by the huge $\gamma$-H-atom hyperfine coupling in the EPR spectrum of the bicyclo[1.1.1]pent-1-yl radical, its cage is by far the most effective such structure at spin transmission. ${ }^{\square, \square \square}$ Radicals 16H - 18H containing carboxylate attached to 1 to 3 such cages (Chart 1) were therefore also chosen for examination. The $\Delta p K_{a}$ values and other data are also in Table 2.

\section{Chart 1. Range of RED-shift: Test Radical Anions}

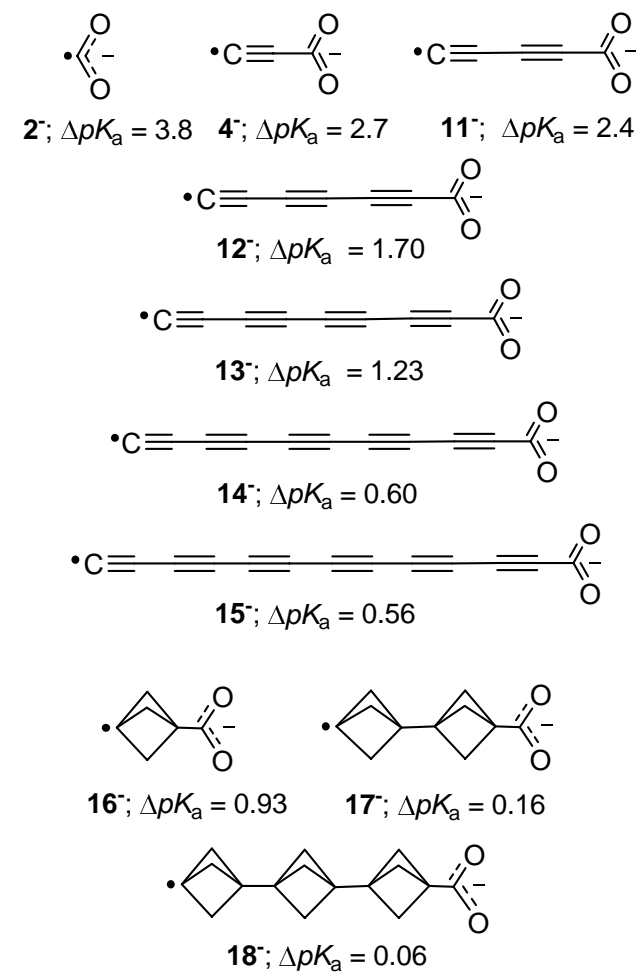

The alkynic series demonstrated that the RED-shift is maintained over a remarkably long distance. Examination of Table 2 (col. 4) showed that the radicals with up to 4 triple bonds separating the charge and spin had $\Delta p K_{a}$ values $>1$ unit. This represents an order of magnitude greater acidity for each radical, than for the corresponding non-radical model. The extent of transmission of the RED-shift for this series is illustrated in Figure 4 which plots $\Delta p K_{a}$ against the number of $\mathrm{C}-\mathrm{C}$ bonds formally separating the carboxylate from the spin. Even out to 12 bonds a RED-shift was still appreciable.

Table 2. DFT Computed Properties for Acid Radicals $11 \mathrm{H}$ to $18 \mathrm{H}$.

\begin{tabular}{l|l|l|l|l|l} 
Species & $\Delta G_{A-H A}$ & $p K_{a}^{d t}$ & $\Delta p K_{a}^{\text {dt }}$ & $\Delta q(O)$ & $\rho(\mathrm{O})$ \\
\hline $\mathbf{1 1 H}$ to $\mathbf{1 1}^{-}$ & -0.402 & -0.13 & 2.40 & -0.061 & 0.053 \\
\hline $\mathbf{1 2 H}$ to $\mathbf{1 2}^{-}$ & 1.40 & 0.39 & 1.70 & -0.044 & 0.032 \\
\hline $\mathbf{1 3 H}$ to $\mathbf{1 3}^{-}$ & 2.44 & 0.69 & 1.23 & -0.032 & 0.021 \\
\hline $\mathbf{1 4 H}$ to $\mathbf{1 4}^{-}$ & 4.07 & 1.16 & 0.60 & -0.022 & 0.014 \\
\hline $\mathbf{1 5 H}$ to $\mathbf{1 5}^{-}$ & 4.70 & 1.34 & 0.56 & -0.015 & 0.010 \\
\hline \hline $\mathbf{1 6 H}$ to $\mathbf{1 6}^{-}$ & 14.80 & 4.24 & 0.93 & -0.028 & 0.012 \\
\hline $\mathbf{1 7 H}$ to $\mathbf{1 7}^{-}$ & 17.73 & 5.08 & 0.16 & -0.003 & 0.0 \\
\hline $\mathbf{1 8 H}$ to $\mathbf{1 8}^{-}$ & 18.17 & 5.21 & 0.06 & -0.001 & 0.0
\end{tabular}

A somewhat different picture emerged for the bicyclo[1.1.1]pentanic series. That the bicyclo[1.1.1]pentane cage was able to effect charge/spin exchange was shown by 
the $\Delta p K_{a}$ value of 0.93 for the first member of the series $\mathbf{1 6 H}$. However the RED-shift was quickly attenuated as additional cages were introduced. The very small $\Delta p K_{a}$ values for $\mathbf{1 7 H}$ and $\mathbf{1 8 H}$ indicate very little RED-shift was transmitted.

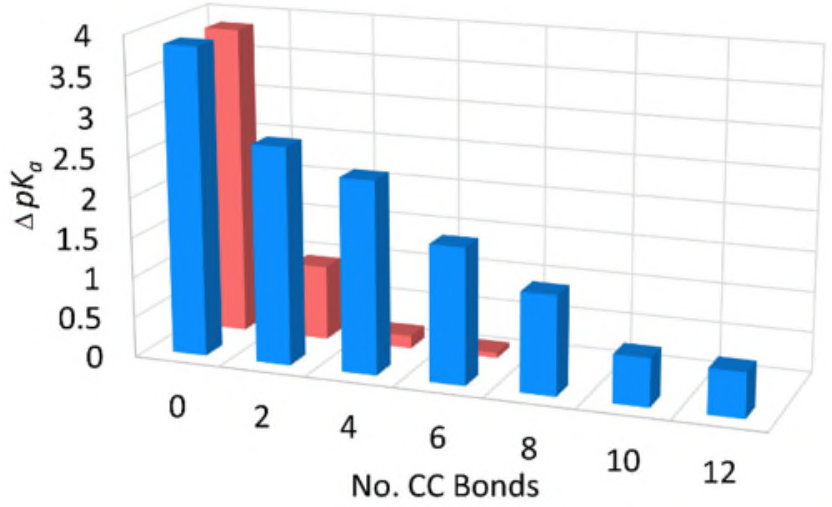

Figure 4. Range of the RED-shift: Plots of $\Delta p K_{a}$ vs the number of $\mathrm{C}-\mathrm{C}$ bonds formally separating the carboxylate charge and the radical spin. Blue cols; alkynyl series $\mathbf{2 H}$, $\mathbf{4 H}$ and $\mathbf{1 1 H}$ to $\mathbf{1 5 H}$. Red cols.: bicyclo[1.1.1]pentyl series $2 \mathrm{H}$ and $16 \mathrm{H}$ to $\mathbf{1 8 H}$.

It is worth noting that the -ve charges on the radical carboxylate groups, relative to those of carboxylate in the non-radical models $\left[\Delta(\mathrm{q}(\mathrm{O})]\right.$ decreased as $\Delta p K_{a}$ decreased for both alkynyl and bicyclo[1.1.1]pentyl series (see Table 2). Similarly the spin densities $\rho(\mathrm{O})$ increased. The picture was similar to that shown in Figure 2 for the original radical series and reflects the same charge/spin exchange process.

\section{Search For Persistent RED-shifted Radicals}

Most of the above radicals were transient species with structures unsuitable for the introduction of bulky substituents to extend their lifetimes. They could be generated to produce a pulse of acidity but other applications would be limited. Isolable radicals were therefore sought that would combine a RED-shift with long lifetimes. 1,5-Dimethyl-6-oxoverdazyl-3-carboxylate $\mathbf{1 9}^{-}$was a known radical anion that persisted in aqueous solutions. ${ }^{\square 1, \square 2}$ The $p K_{a}$ and $\Delta p K_{a}$ of $\mathbf{1 9 H}$ and the related 2,6-dimethyl-5-oxo-4,5-dihydro-pyrimidine-2-carboxylic acid $20 \mathrm{H}$ were computed and are displayed on Chart 2. Neither radical had an appreciable REDshift.

Persistent radicals based on the nitroxide (aminoxyl) moiety are available in great abundance. The nitronyl-nitroxides 4,4,5,5-tetramethyl-imidazolyl-3-oxyl-2-carboxylic acid $\mathbf{2 1 H}$ and its conjugate base $\mathbf{2 1}^{-}$are isolable stable compounds. ${ }^{\square}$ The computed $p K_{a}$ of $\mathbf{2 1 H}$ showed it was a strong acid and the derived $\triangle p K_{a}$ indicated an appreciable REDshift (see Chart 2). Nitronyl-nitroxides with 2-alkynic substituents have also been prepared. The computed $\Delta p K_{a}$ for 22H with an alkyne spacer between the nitronyl nitroxide and the carboxylate suggested a small RED-shift (0.4) was transmitted. Many variations on the nitronyl-nitroxide theme, including benzimidazolyl types, can be accessed.
Probably therefore, numerous stable radical-enhanced acids of this type could be obtained.

Stable dialkyl and diaryl nitroxides exist in even greater variety. Computations with the $t$-butyl-2-carboxyethynyl nitroxide $\mathbf{2 3 H}$ predicted it would be a strong acid with an appreciable RED-shift (1.34) (see Chart 2). These results demonstrate that enhancement of acidity is not confined to $\mathrm{C}$-centered radicals but that nitroxyl radicals induce similar rapid deprotonation. In addition they show that a library of stable, potential RED-shift compounds could be assembled from this compound class. Nitroxide radicals can exist in equilibrium with suitable alkoxyamines and this property is applied in nitroxide mediated radical polymerizations (NMP). For example 23H could probably be obtained by heating a precursor such as $\mathbf{2 4}$. This opens the door to a method for temperature control of $p H$.
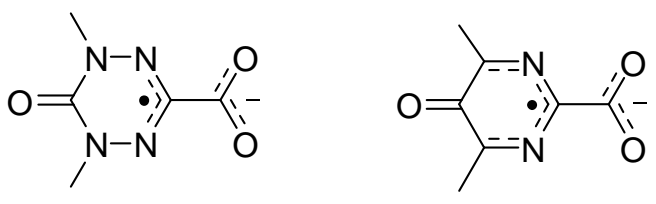

$$
\begin{aligned}
19-p K_{\mathrm{a}} & =3.92 \\
\Delta p K_{\mathrm{a}} & =-1.34
\end{aligned}
$$

$$
2^{-} ; p K_{\mathrm{a}}=2.85
$$$$
\Delta p K_{\mathrm{a}}=0.11
$$
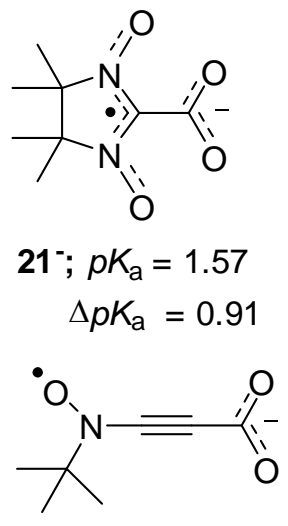

$$
\begin{array}{r}
{\text { 23- } ; p K_{\mathrm{a}}}^{=}=2.77 \\
\Delta p K_{\mathrm{a}}=1.34
\end{array}
$$

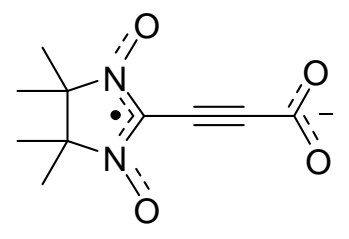

$$
\begin{array}{r}
22^{-} ; p K_{\mathrm{a}}=1.93 \\
\Delta p K_{\mathrm{a}}=0.40
\end{array}
$$

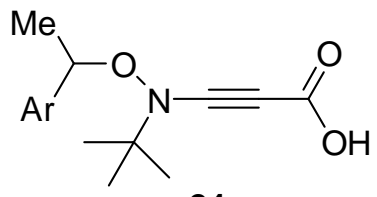

24

\section{Chart 2. Potential Persistent Radical-enhanced Acids.}

\section{CONCLUSIONS}

Known $p K_{a}$ data revealed that the phenomenon of radicalenhanced Brønsted acidity was real for bicarbonate, carboxyl and hydroperoxyl radicals. A DFT method of obtaining $p K_{a}$ s corroborated this and enabled a scale for quantifying it to be developed. Using this approach, predicted $\Delta p K_{a}$ values were derived for a representative set of diverse radicals. Appreciable RED-shifts were found for radicals whose conjugate anions had frontier orbitals permitting re-distribution of negative charge away from their anionic O-atoms and spin density away from their radical centers. The ethynyl group was shown to be a marvelously efficient transmitter of 
the effect such that RED-shift was still measurable in species with 6 triple bonds formally separating charge and spin. The bicyclo[1.1.1]pentane cage was superior as a spacer to other $\mathrm{sp}^{3}$ and $\mathrm{sp}^{2}$ chains; but charge/spin exchange was strongly attenuated by more than one such cage.

That the phenomenon was not confined to C-centered radicals was substantiated by computations with nitroxide radicals containing carboxylate substituents. Furthermore, the likelihood is that stable, RED-shifted radicals of this class could be prepared and isolated. It is probable too that acids of other types, such as sulfonic and phosphonic, with structures containing appropriately situated radical centers, would also display enhanced acidity.

The occurrence of radical-enhanced dissociation of acids raises the possibility that nearby spins might enhance other types of dissociation. For example, generation of the radical $\cdot \mathrm{XC}(=\mathrm{O}) \mathrm{OCR}_{3}(\mathrm{X}=\mathrm{O}, \mathrm{NH}, \mathrm{C} \equiv \mathrm{C}$ etc.) might induce rapid dissociation to ${ }^{\bullet} \mathrm{XC}(=\mathrm{O}) \mathrm{O}^{-}$and carbocations $\mathrm{R}_{3} \mathrm{C}^{+}$.

In aqueous solutions most of the RED-shift radicals will be extensively dissociated such that the chemistry is expected

\section{REFERENCES AND NOTES}

(1) Liochev, S. I.; Fridovich, I. Mechanism of the peroxidase activity of $\mathrm{Cu}, \mathrm{Zn}$ superoxide dismutase. Free Radical Biol. Med. 2010, 48, $1565-1569$.

(2) Ramirez, D. C.; Gomez-Mejiba, S. E.; Corbett, J. T.; Deterding, L. J.; Tomer, K. B.; Mason, R. P. Cu,Zn-Superoxide Dismutase-driven Free Radical Modifications: Copper- and Carbonate Radical Anion-initiated Protein Radical Chemistry. Biochem. J. 2009, 417, 341-353.

(3) Bonini, M. G.; Miyamoto, S.; Di Mascio, P.; Augusto, O. Production of the Carbonate Radical Anion During Xanthine Oxidase Turnover in the Presence of Bicarbonate. J. Biol. Chem. 2004, 279, 51836-51843.

(4) Liochev, S. I.; Fridovich, I. Copper, Zinc Superoxide Dismutase and $\mathrm{H}_{2} \mathrm{O}_{2}$. Effects of Bicarbonate on Inactivation and Oxidations of NADPH and Urate, and on Consumption of $\mathrm{H}_{2} \mathrm{O}_{2}$. J. Biol. Chem. 2002, 277, 34674-34678.

(5) Francisco, J. S.; Muckerman, J. T.; Yu, H.-G. HOCO Radical Chemistry. Acc. Chem. Res. 2010, 43, 1519-1526.

(6) Favaudon, V.; Tourbez, H.; Houee-Levin, C.; Lhoste, J. M. Carboxyl Radical Induced Cleavage of Disulfide Bonds in Proteins. A $\gamma$-Ray and Pulse Radiolysis Mechanistic Investigation. Biochemistry 1990, 29, 1097889.

(7) (a) Griffith, S. M.; Hansen, R. F.; Dusanter, S.; Stevens, P. S.; Alaghmand, M.; Bertman, S. B.; Carroll, M. A.; Erickson, M.; Galloway, M.; Grossberg, N.; Hottle, J.; Hou, J.; Jobson, B. T.; Kammrath, A.; Keutsch, F. N.; Lefer, B. L.; Mielke, L. H.; O'Brien, A.; Shepson, P. B.; Thurlow, M.; Wallace, W.; Zhang, N.; Zhou, X. L. OH and HO2 Radical Chemistry During PROPHET 2008 and CABINEX 2009 - Part 1: Measurements and Model Comparison. Atmospheric Chem. Phys. 2013, 13, 5403-5423.

(8) Yin, H; Xu, L.; Porter, N. A. Free Radical Lipid Peroxidation: Mechanisms and Analysis. Chem. Rev. 2011, 111, 5944-5972;

(9) Aikens, J.; Dix, T. A. Hydrodioxyl (perhydroxyl), Peroxyl, and Hydroxyl Radical-initiated Lipid Peroxidation of Large Unilamellar Vesicles (Liposomes): Comparative and Mechanistic Studies. Arch. Biochem. Biophys. 1993, 305, 516-25. to be that of the negatively charged conjugate radical anions. However, in hydrocarbon-like or lipid environments the neutral radical forms of bicarbonate, carboxyl and hydroperoxyl are expected to contribute and to show different activity to the conjugate radical anions.

\section{ASSOCIATED CONTENT}

\section{Supporting Information}

The Supporting Information is available free of charge on the ACS Publications website at DOI:

Computational Methods, Deprotonation Free Energies of Model Acids, Cartesian coordinates for computed structures.

\section{AUTHOR INFORMATION}

\section{Corresponding Author}

*E-mail: jcw@st-andrews.ac.uk.

Tel: 44(0)1334 463864

\section{ORCID}

John C. Walton: 0000-0003-2746-6276

\section{ACKNOWLEDGMENT}

JCW thanks EaStCHEM for financial support.
(10) Czapski, G.; Lymar, S. V.; Schwarz, H. A. J. Phys. Chem. A, Acidity of the Carbonate Radical. 1999, 103, 3447-3450.

(11) Bisby, R. H.; Johnson, S. A.; Parker, A. W.; Tavender, S. M. Timeresolved Resonance Raman Spectroscopy of the Carbonate Radical. J. Chem. Soc. Faraday Trans. 1998, 94, 2069-2072.

(12) Chawla, O. P.; Fessenden, R. W. Electron Spin Resonance and Pulse Radiolysis Studies of Some Reactions of Peroxysulfate. J. Phys. Chem., 1975, 79, 2693-2700.

(13) Armstrong, D. A.; Waltz, W. L.; Rauk, A. Carbonate Radical Anion - Thermochemistry. Can. J. Chem. 2006, 84, 1614-1619.

(14) Bühl, M.; DaBell, P.; Manley, D. W.; McCaughan, R. P.; Walton, J. C. Bicarbonate and Alkyl Carbonate Radicals: Structural Integrity and Reactions with Lipid Components. J. Am. Chem. Soc. 2015, 137, $16153-16162$

(15) Jeevarajan, A. S.; Carmichael, I.; Fessenden, R. W. ESR Measurement of the pKa of Carboxyl Radical and ab initio Calculation of the Carbon-13 Hyperfine Constant. J. Phys. Chem. 1990, 94, 1372-1376.

(16) Behar, D.; Czapski, G.; Rabani, J.; Dorfman, L. M.; Schwarz, H. A Acid Dissociation Constant and Decay Kinetics of the Perhydroxyl Radical. J. Phys. Chem. 1970, 74, 3209-3213

(17) Bielski, B. H. J.; Cabelli, D. E.; Arudi, R. L.; Ross, A. B. Reactivity of Perhydroxyl/Superoxide Radicals in Aqueous Solution. J. Phys. Chem. Ref. Data 1985, 14, 1041-1100

(18) Nam, E.; Alokolaro, P. E.; Swartz, R. D.; Gleaves, M. C.; Pikul, J.; Kovacs, J. A. Investigation of the Mechanism of Formation of a ThiolateLigated Fe(III)-OOH. Inorganic Chem. 2011, 50, 1592-1602.

(19) Serjeant, E. P.; Dempsey, B. Ionisation Constants of Organic Acids in Aqueous Solution; IUPAC Chemistry Data Series No. 23; Pergamon Press: Oxford, U.K., 1979.

(20) Kortum, G.; Vogel, W.; Andrussow, K. Dissociation Constants of Organic Acids in Aqueous Solution; Butterworths: London, 1961.

(21) Perrin, D. D. Dissociation Constants of Organic Bases in Aqueous Solution Supplement; Butterworths: London, 1972; Perrin, D. D. Dissociation Constants of Organic Bases in Aqueous Solution; Butterworths: London, 1965. 
(22) Hayon, E.; Simic, M. Acid-base Properties of Free Radicals in Solution, Acc. Chem. Res. 1974, 7, 114-121.

(23) Morris, M.; Chan, B.; Radom, L. Effect of Protonation State and Interposed Connector Groups on Bond Dissociation Enthalpies of Alcohols and Related Systems. J. Phys. Chem. A 2014, 118, 2810-2819.

(24) Mayer, P. M.; Radom, L. Deprotonating Molecules and Free Radicals to Form Carbon-Centered Anions: A G2 ab Initio Study of Molecular and Free Radical Acidity. J. Phys. Chem. A 1998, 102, 4918-4924.

(25) Mayer, P. M.; Glukhovtsev, M. N.; Gauld, J. W.; Radom, L. The Effects of Protonation on the Structure, Stability, and Thermochemistry of Carbon-Centered Organic Radicals. J. Am. Chem. Soc. 1997, 119, 12889-12895.

(26) Frisch, M. J.; Trucks, G. W.; Schlegel, H. B.; Scuseria, G. E.; Robb, M. A.; Cheeseman, J. R.; Scalmani, G.; Barone, V.; Mennucci, B.; Petersson, G. A.; Nakatsuji, H.; Caricato, M.; Li, X.; Hratchian, H. P.; Izmaylov, A. F.; Bloino, J.; Zheng, G.; Sonnenberg, J. L.; Hada, M.; Ehara, M.; Toyota, K.; Fukuda, R.; Hasegawa, J.; Ishida, M.; Nakajima, T.; Honda, Y.; Kitao, O.; Nakai, H.; Vreven, T.; Montgomery, J. A., Jr.; Peralta, J. E.; Ogliaro, F.; Bearpark, M.; Heyd, J. J.; Brothers, E.; Kudin, K. N.; Staroverov, V. N.; Kobayashi, R.; Normand, J.; Raghavachari, K.; Rendell, A.; Burant, J. C.; Iyengar, S. S.; Tomasi, J.; Cossi, M.; Rega, N.; Millam, J. M.; Klene, M.; Knox, J. E.; Cross, J. B.; Bakken, V.; Adamo, C.; Jaramillo, J.; Gomperts, R.; Stratmann, R. E.; Yazyev, O.; Austin, A. J.; Cammi, R.; Pomelli, C.; Ochterski, J. W.; Martin, R. L.; Morokuma, K.; Zakrzewski, V. G.; Voth, G. A.; Salvador, P.; Dannenberg, J. J.; Dapprich, S.; Daniels, A. D.; Farkas, Ö.; Foresman, J. B.; Ortiz, J. V.; Cioslowski, J.; Fox, D. J. Gaussian 09, Revision D.01; Gaussian, Inc.: Wallingford, CT, 2013.

(27) Cheng, J.; Liu, X.; Van de Vondele, J.; Sulpizi, M.; Sprik, M. Redox Potentials and Acidity Constants from Density Functional Theory Based Molecular Dynamics. Acc. Chem. Res. 2014, 47, 3522-3529.

(28) Zevatskii, Y. E.; Samoilov, D. V. Russ. J. Org. Chem. Modern Methods for Estimation of Ionization Constants of Organic Compounds in Solution. 2011, 47, 1445-1467.

(29) Schmidt am Busch, M; Knapp, E.-W. Accurate pKa Determination for a Heterogeneous Group of Organic Molecules. ChemPhysChem 2004, $5,1513-1522$

(30) Silva, C. O.; da Silva, E. C.; Nascimento, M. A. C. Ab initio Calculations of Absolute pKa Values in Aqueous Solution. Part 2. Aliphatic Alcohols, Thiols, and Halogenated Carboxylic Acids. J. Phys. Chem. A 2000, 104, 2402-2409.

(31) Klicic, J. J.; Freisner, R. A.; Liu, S.-Y.; Guida, W. C. Accurate Prediction of Acidity Constants in Aqueous Solution via Density Functional Theory and Self-Consistent Reaction Field Methods. J. Phys. Chem. A 2002, 106, 1327-1335.

(32) Klamt, A.; Eckert, F.; Diedenhofen, M.; Beck, M. E. First Principles Calculations of Aqueous pKa Values for Organic and Inorganic Acids Using COSMO-RS Reveal an Inconsistency in the Slope of the pKa Scale. $J$. Phys. Chem. A 2003, 107, 9380-9386.

(33) Liptak, M. D.; Gross, K. C.; Seybold, P. G.; Feldgus, S.; Shields, G. C. Absolute pKa Determinations for Substituted Phenols. J. Am. Chem. Soc. 2002, 124, 6421-6427.

(34) Kaminski, G. A. Accurate Prediction of Absolute Acidity Constants in Water with a Polarizable Force Field: Substituted Phenols, Methanol, and Imidazole. J. Phys. Chem. B 2005, 109, 5884-5890.

(35) Han, J.; Tao, F-M. Correlations and Predictions of pKa Values of Fluorophenols and Bromophenols Using Hydrogen-Bonded Complexes with Ammonia. J. Phys. Chem. A 2006, 110, 257-263.

(36) Eckert, F.; Klamt, A. Accurate prediction of basicity in aqueous solution with COSMO-RS. J. Comput. Chem. 2006, 27, 11-19.

(37) Zhang, S.; Baker, J.; Pulay, P. A Reliable and Efficient First Principles-Based Method for Predicting pKa Values. 1. Methodology. J. Phys. Chem. A 2010, 114, 425-431.

(38) Zhang, S.; Baker, J.; Pulay, P. A Reliable and Efficient First Principles-Based Method for Predicting pKa Values. 2. Organic Acids. J. Phys. Chem. A 2010, 114,432-442.

(39) Curtiss, L. A.; Redfern, P. C.; Raghavachari, K. Gaussian-4 Theory. J. Chem. Phys. 2007, 126, 84108-84119.

(40) Yanai, T.; Tew, D. P.; Handy, N. C. A New Hybrid Exchange-Correlation Functional Using the Coulomb-attenuating Method (CAMB3LYP). Chem. Phys. Lett. 2004, 393, 51-57.

(41) Barone, V.; Cossi, M. Quantum Calculation of Molecular Energies and Energy Gradients in Solution by a Conductor Solvent Model. J. Phys. Chem. A, 1998, 102, 1995-2001.

(42) Tissandier, M. D.; Cowen, K. A.; Feng, W. Y.; Gundlach, E.; Cohen, M. H.; Earhart, A. D.; Coe, J. V.; Tuttle,T. R. The Proton's Absolute
Aqueous Enthalpy and Gibbs Free Energy of Solvation from Cluster-Ion Solvation Data. J. Phys. Chem. A, 1998, 102, 7787-7794

(43) Empirical ChemAxon prediction see: https://www.drugbank.ca/drugs/DB04261.

(44) Berndt, A.; Fischer, H.; Paul, H. in Landolt-Börnstein, Vol. 9b, ed. Fischer, H, Hellwege, K.-H., Springer, Berlin, 1977.

(45) Neugebauer, F. A. in Landolt-Börnstein, Vol. 17b, ed. Fischer, H. Springer, Berlin, 1987.

(46) Berndt, A. in Landolt-Börnstein, Vol 17c, ed. Fischer, H. Springer, Berlin, 1987.

(47) Walton, J. C. Bridgehead Radicals. Chem. Soc. Rev. 1992, 21, 105112

(48) . Della, E. W.; Head, N. J.; Mallon, P.; Walton, J. C. Homolytic Reactions of Cubanes. Generation and Characterization of Cubyl and Cubylcarbinyl Radicals. J. Am. Chem. Soc., 1992, 114, 10730 - 10738.

(49) Maillard, B.; Walton, J. C. An ESR Study of Bicyclo[1.1.1]pent-1yl Radicals. J. Chem. Soc., Chem. Commun. 1983, 900-901.

(50) Adcock, W.; Binmore, G. T.; Krstic, A. R.; Walton, J. C.; Wilkie, J. Cross Cage Interactions in Substituted Bicyclo[1.1.1]pent-1-yl Radicals. Dissociation to [1.1.1]Propellane. J. Am. Chem. Soc., 1995, 117, 27582766.

(51) (a) Barclay, T. M.; Hicks, R. G.; Lemaire, M. T.; Thompson, L. K.; $\mathrm{Xu}, \mathrm{Z}$. Synthesis and Coordination Chemistry of a Water-soluble Verdazyl Radical. Structures and Magnetic Properties of $\mathrm{M}(\mathrm{H} 2 \mathrm{O}) 2(\mathrm{vdCO} 2) 2 \cdot 2 \mathrm{H} 2 \mathrm{O}$ ( $\mathrm{M}=\mathrm{Co}, \mathrm{Ni}$; vdCO2 = 1,5-dimethyl-6-oxo-verdazyl-3-carboxylate). Chem. Commun. 2002, 1688-1689.

(52) Kamebuchi, H.; Okubo, M; Okazawa, A.; Enomoto, M.; Harada, J.; Ogawa, K.; Maruta, G.; Takeda, S.; Kojima, N.; Train, C.; Verdaguer, M. A Tricky Water Molecule Coordinated to a Verdazyl Radical-iron(II) Complex: a Multi-technique Approach. Phys. Chem. Chem. Phys. 2014, 16, 9086-9095

(53) Boocock, D. G. B.; Darcy, R.; Ullman, E. F. Studies of Free Radicals. II. Chemical Properties of Nitronylnitroxides. A Unique Radical Anion. J. Am. Chem. Soc. 1968, 90, 5945-5946.

(54) Ullman, E. F.; Osieck, J. H.; Boocock, D. G. B.; Darcy, R. Stable Free Radicals. X. Nitronyl Nitroxide Monoradicals and Biradicals as Possible Small Molecule Spin Labels. J. Am. Chem. Soc. 1972, 94, 7049-7059.

(55) Nicolas, J.; Guillaneuf, Y.; Lefay, B.; Bertin, D.; Gigmes, D.; Charleux, B. Nitroxide-mediated Polymerization. Prog. Polym. Sci. 2013, 38 , 63-325.

(56) Tebben, L.; Studer, A. Nitroxides: Applications in Synthesis and in Polymer Chemistry. Angew. Chem. Int. Ed. 2011, 50, 5034-5068.

\section{ToC Graphic}

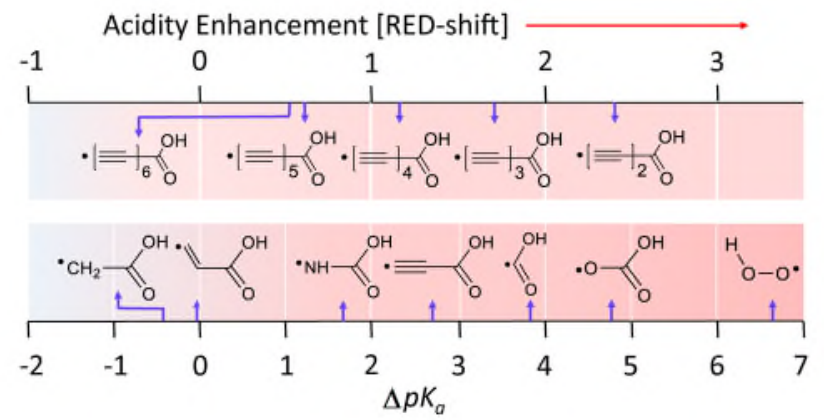

